\title{
Relação escola-família: Desafios da pandemia Covid-19 e do ensino remoto emergencial sob a ótica docente
}

School-family relationships: Challenges of the Covid-19 pandemic and emergency remote teaching

from the teacher's perspective

Relación escuela-familia: Desafíos de la pandemia Covid-19 y la enseñanza remota de emergencia

desde la perspectiva docente

Recebido: 11/12/2021 | Revisado: 15/12/2021 | Aceito: 23/12/2021 | Publicado: 25/12/2021

\author{
Celia Nonato \\ ORCID: https://orcid.org/0000-0002-5842-2076 \\ Universidade Salgado de Oliveira, Brasil \\ E-mail: celianon2108@gmail.com \\ Maria Angela Mattar Yunes \\ ORCID: https://orcid.org/0000-0002-4653-3895 \\ Universidade Salgado de Oliveira, Brasil \\ E-mail: mamyunes@gmail.com \\ Célia Regina Rangel Nascimento \\ ORCID: https://orcid.org/0000-0002-3175-0715 \\ Universidade Federal do Espírito Santo, Brasil \\ E-mail:celia.nascimento@ufes.br
}

\begin{abstract}
Resumo
Esta pesquisa investigou os desafios da relação escola-família, durante a pandemia da COVID-19 e do ensino remoto emergencial, por meio da percepção dos professores. Realizou-se uma pesquisa exploratória de corte transversal e abordagem qualitativa. Participaram 106 professores da educação básica de escolas localizadas no Estado do Rio de Janeiro que responderam a Escala Relação Família Escola (RFE), adaptada e abreviada para a pesquisa e uma questão aberta relacionada aos desafios da relação escola-família na pandemia. Os resultados das análises quali-quantitativa revelaram que os professores reconhecem que o bom relacionamento entre a escola e a família traz benefícios para desenvolvimento dos estudantes. No entanto, culpabilizam às famílias pelos problemas que alunos apresentam na escola, desconfiam da qualidade do apoio dos pais no acompanhamento de estudos dos filhos e apontam que os mesmos não se interessam pelas atividades educativas. Com a pandemia, os professores destacaram alguns desafios de ordem sistêmica ao lidar com as famílias, envolvendo os processos de comunicação, de relacionamentos proximais, de desigualdades e injustiças sociais e de riscos à saúde socioemocional desses atores. Em conclusão, sugere-se ampliar a discussão no tocante à formação profissional de professores sobre mecanismos positivos de interações escola família, como a participação ativa e a cooperação dos pais nas experiências educacionais das crianças e adolescentes.
\end{abstract}

Palavras-chave: COVID-19; Crise social; Processo educacional; Relação escola família.

\begin{abstract}
This research investigated the challenges of the school-family relationships during the COVID-19 pandemic and emergency remote teaching through the teacher's perspective. It was conducted an exploratory cross-sectional research and a qualitative approach, involving 106 primary education teachers from schools located in the State of Rio de Janeiro. The educators answered the family-school relationship scale - adapted and shortened for the current study - and also an open question related to the challenges of the school-family relationships in the pandemic. The results of the quali-quantitative analysis revealed that teachers recognize that a good relationship between school and family is beneficial for the development of students. However, they blame the families for the issues that students face at school, distrust the quality of parental support in monitoring their children's studies, and point out that students are not interested in educational activities. Due to the pandemic, teachers highlighted some systemic challenges such as dealing with families, communication processes, proximal relationships, social inequalities and injustices, and the risks to the socio-emotional health of these actors. In conclusion, it is suggested to stimulate the discussion regarding the professional training of teachers on positive mechanisms of school-family interactions, such as the active participation and cooperation of parents in the educational experiences of children and adolescents.
\end{abstract}

Keywords: COVID-19; Social crisis; Educational process; School-family relationships.

\section{Resumen}

Esta investigación investigó los desafíos de la relación escuela-familia durante la pandemia COVID-19 y la enseñanza 
remota de emergencia desde la percepción de los profesores. Se realizó una investigación exploratoria transversal con enfoque cualitativo. Participaron 106 maestros de educación primaria de escuelas ubicadas en el estado de Rio de Janeiro que respondieron la Escala de Relación Escuela-Familia (RFE), adaptada y abreviada para la investigación y la pregunta relacionada con los desafíos de la relación escuela-familia en la pandemia. Los resultados de los análisis cuali-cuantitativos revelaron que los docentes reconocen que una buena relación entre la escuela y la familia trae beneficios para el desarrollo de los estudiantes. Sin embargo, culpan a las familias por los problemas que tienen los alumnos en la escuela, desconfían de la calidad del apoyo de los padres en el seguimiento de los estudios de sus hijos y señalan que no les interesan las actividades educativas. Con la pandemia, los docentes destacaron algunos desafíos sistémicos en el trato con las familias, involucrando los procesos de comunicación, relaciones cercanas, desigualdades e injusticias sociales, y riesgos para la salud socioemocional de estos actores. En conclusión, se sugiere ampliar la discusión sobre la formación profesional de los docentes sobre los mecanismos positivos de las interacciones escuelafamilia, como la participación activa y la cooperación de los padres en las experiencias educativas de los niños y adolescentes.

Palabras clave: COVID-19; Crisis social; Proceso educativo; Relación escuela-familia.

\section{Introdução}

Ao anunciar que "É preciso uma aldeia inteira para educar uma criança", o provérbio africano traduz uma sabedoria milenar acerca da responsabilidade coletiva de diferentes atores e contextos na educação e no desenvolvimento humano. As pesquisas contemporâneas sobre relação escola família se aproximam desses ensinamentos trazidos das aldeias ao afirmarem que ações cooperativas, envolvendo escola-família-comunidade favorecem as novas gerações (Epstein, 1982,1987, 2011; 2018).

Os estudos, e ainda mais, a prática pedagógica de professores e gestores, põe em evidência as influências positivas do relacionamento escola-família para o desenvolvimento das crianças e adolescentes. Na maior parte dos casos, os estudantes desenvolvem um autoconceito positivo, melhoram o desempenho acadêmico, apresentam maior senso responsabilidade e autonomia, além de estabelecerem relações interpessoais mais cooperativas e amistosas (Bhering \& Siraj-Blatchford,1999; Epstein, 1982, 1987, 2018; Hornby \& Lafaele, 2011; Smith et al., 2018; Willemse et al., 2018). Vale destacar que a relação dessa parceria propicia também a redução do absenteísmo e de evasão escolar, levando os estudantes a expectar realizações futuras com o prosseguimento dos estudos (Epstein, 2011; Hornby \& Lafaele, 2011; Lee, 2018; Polonia \& Dessen, 2005; Richmond, 2017; Wagner et al.,2019).

Em muitas sociedades democráticas espera-se que a família participe ativamente das ações e resoluções da escola por meio do conselho escolar, do conselho de classe, da associação de pais e mestres e do grêmio escolar (Antunes, 2016). Todavia, ainda são identificados conflitos e fragilidades que obstaculizam a participação efetiva de atores na construção dessa parceria (Glidden, 2018), particularmente quando há ideias pré-concebidas a respeito das famílias. A marginalização das famílias pode ser identificada em reclamações dos professores, em situações que envolvem constrangimentos e humilhações dos pais, além de pedido de socorro dos profissionais de educação para resolver problemas de disciplina dos alunos (Glidden,2018; Patto,1990; Polonia \& Dessen, 2005; Saraiva-Junges \& Wagner, 2013). Além disso, profissionais de saúde e educação apresentam crenças que sustentam que as famílias pobres estão perdidas, confusas, desestruturadas (Saraiva-Jungles \& Wagner, 2013; Nonato et al.,2007) ou são negligentes, desinteressadas e pouco participativas nos processos educativos (Polonia \& Dessen, 2005; Saraiva-Junges \& Wagner, 2013). A conotação estigmatizante das palavras usadas e a burocracia praticada nos ambientes escolares marcam a ascendência da escola sobre as famílias (Faria \& Meneghetti, 2011). Mecanismos como esses, de dominação e subjugação, evidenciam o desequilíbrio de poder engendrados nas práticas dos cotidianos escolares, negando a face dos processos de resiliência das famílias pobres (Matos et al., 2018; Yunes \& Szymanski,2003; Yunes et al.,2007). O aprofundamento da temática, pode ser identificado em resquícios de crenças culturais do colonialismo, em especial, de práticas racistas com as famílias e alunos negros (Algebaile, 2009; Melo et al., 2017; Patto,2000). 
O contraponto a essa violência está em teorias e pesquisas empíricas que demonstram que a colaboração eficaz entre pais e professores é um fator crítico para o desenvolvimento acadêmico e socioemocional dos alunos do ensino fundamental e ensino médio (Epstein, 2011; Wagner et al.,2019; Willemse et al.,2018). Portanto, não é surpreendente que as políticas nacionais promovam cada vez mais essa colaboração entre pais e professores (Sanders \& Epstein,2005; Epstein, 2018). Não é por acaso que Willemse e colaboradores (2018) afirmam que a luta para abordar a questão na formação de professores se dá por muitos programas voltados à relação escola família em vários países europeus. Todavia, no Brasil, embora existam leis que amparem essas ações, a revisão sistemática de literatura realizada por Saraiva-Junges \& Wagner (2016) aponta que ainda há uma importante lacuna no que tange às intervenções efetivas que apresentem soluções voltadas à relação escola família.

Em tese, tais programas buscam apoiar os professores em diferentes áreas, mas especialmente no lidar com as famílias e com as comunidades (Epstein, 2018; Gârţu, 2017; Lee, 2018; Martínez-González et al., 2016; Rodrigo, Almeida \& Reichle, 2015; Saraiva-Junges \& Wagner,2016). Alguns programas oferecem orientação de pais de modo a propiciar conhecimentos acerca da parentalidade positiva para famílias de escolares (Gârţu, 2017, Martínez-González et al., 2008; Rodrigo et al.,2015). $\mathrm{Na}$ maior parte dos casos, as orientações versam sobre habilidades de autorregulação emocional, autoestima e assertividade, estratégias de comunicação, resolução de conflitos e negociação, limites e disciplina positiva. Decerto que ações de apoio às famílias, especialmente em comunidades de baixa renda, podem ajudar a reduzir as disparidades de raça e renda (Rodrigo et al.,2015).

É fato público e notório que o acontecimento histórico da pandemia Covid-19 trouxe novos paradigmas para o sistema educacional, ocasionado pelo fechamento das escolas e a implementação do ensino remoto emergencial (Bozkut et al., 2020; Cluver et al., 2020; Crescenza et al., 2021; Moura et al.,2020). Por envolver processos, pessoas, contextos e o tempo dado às mudanças, vulnerabilidades, reorganizações e interferências, buscou-se inspiração no modelo PPCT (processo-pessoacontexto-tempo) da Teoria Bioecológica do Desenvolvimento Humano (TBDH) (Bronfenbrenner \& Morris, 1998). À guisa de explicação, o primeiro elemento no modelo, interações significativas denominadas processos proximais, é entendido enquanto força propulsora do desenvolvimento humano e ocupam posição central na teoria (Bronfenbrenner \& Morris, 1998). O segundo elemento no modelo refere-se à Pessoa, cujas características de força, recursos e demandas podem ser geradoras ou disruptivas, favorecer ou inibir os processos proximais, força motriz do desenvolvimento. Como conceito chave da teoria, o processo proximal representa as formas de interação do organismo com o ambiente, que ocorrem regularmente, moldando a forma, a força, o conteúdo e a direção dos resultados no desenvolvimento humano (Bronfenbrenner \& Evans, 2000). O terceiro elemento refere-se aos níveis contextuais (microssistema, mesossistema, exossistema e macrossistema). O microssistema foi definido como o ambiente físico, social e simbólico em que a pessoa se insere e interage face a face com outras pessoas. O mesossistema foi descrito como um sistema de microssistemas, ou seja, a relação entre dois ou mais microssistemas em que a pessoa se insere, como a relação família escola aqui discutida. O exossistema diz respeito aos microssistemas em que a pessoa não participa ativamente por meio de interações face a face, mas que influenciam e são influenciados pela pessoa. $O$ macrossistema se refere aos sistemas institucionais e de valores de uma cultura, relacionando-se a aspectos econômicos, sociais, educacionais, legais e políticos (Bronfenbrenner, 1979). O quarto elemento refere-se ao Tempo, a perspectiva cronossistêmica da teoria. Na perspectiva histórica, o macrotempo corresponde aos acontecimentos históricos, que impactam não apenas o indivíduo, mas pequenos e grandes grupos (Bronfenbrenner \& Morris, 1998). A partir desse modelo é possível compreender que existe interconexão entre as pessoas e seus contextos, ou seja, entre a cultura, crenças, valores, atitudes que se atualizam nas relações. Ante ao exposto, segue a questão que orienta esta pesquisa. 


\section{Como os professores percebem a relação escola-família em tempo de Covid-19 e de ensino remoto?}

A pandemia COVID-19 tornou os ambientes domésticos essenciais e, em muitos casos, o único local possível de aprendizagem formal para os alunos (Richmond et al.,2020). Essa mudança aproximou ainda mais os pais, responsáveis e outros membros do microsssitema familiar, da educação das crianças e adolescentes. Um mundo de experiências e oportunidades únicas de interação construtiva se tornaram possíveis nesse período com a possibilidade de maior envolvimento, proteção e participação ativa no acompanhamento do desenvolvimento das crianças e dos adolescentes (Ferrara et al., 2021; Magalhães et al.,2021).

Com o trabalho escolar reconfigurado pela pandemia e pelas plataformas online, os professores foram impelidos a usar as ferramentas digitais como único recurso pedagógico para entregar conteúdo online para os alunos. As famílias, sobrecarregadas pelo acúmulo de tarefas que lhes foram atribuídas, tiveram que, além de outras tarefas, supervisionar o ensino remoto dos filhos no espaço doméstico (Richmond et al., 2020). Decerto que os impactos a longo prazo dessas mudanças ainda são desconhecidos (Negri et al., 2020). No entanto, essa incerteza reafirma as oportunidades para alavancar os ambientes domésticos e comunitários como espaço de conhecimento que merecem maior atenção de professores e educadores de modo geral (Epstein, 2018). Tradicionalmente, o conhecimento e o saber nas escolas se manifestam por meio de ideologias valorizadas pela sociedade, e são ensinados e aprendidos por meio do currículo estabelecido (Apple, 2018). A pandemia está oportunizando que professores e formadores de professores a conheçam as casas e as comunidades para atender às necessidades específicas de alunos do ensino fundamental e médio (Richmond,2020).

Não é de hoje, que alguns formadores de professores têm como meta envolver os futuros professores para aprender com e a partir de famílias e comunidades (Epstein, 2018; Richmond, 2017). Deve-se ressaltar que esse interesse vai ao encontro do consenso teórico de corresponsabilidade escola família comunidade (Bronfenbrenner \& Morris, 1998; Epstein, 2011, 2018; Semke, Sheridan, 2012; Smith et al, 2020), o que no Brasil, é uma prerrogativa legal nos ditos legais do art. 205 da Constituição Federal do Brasil de 1988. Destarte, qualquer nação do mundo regida por uma Constituição com concepções democráticas precisa de escolas que façam parceria com as famílias e a comunidade para efetivamente educar as novas gerações sob os princípios e valores pautados no respeito à maioria, à igualdade e à liberdade (Epstein, 2018; Gârţu, 2017; Lee, 2018; Martínez-González et al., 2016; Richamond, 2017; Rodrigo, Almeida \& Reichle, 2015; Szymanski,1982). Entretanto, poucos estudos científicos têm se dedicado a compreender de forma sistemática o funcionamento do fenômeno relacional entre a escola e a família (Picanço, 2012). Desse modo, até aqui, pode-se afirmar que o imediatismo da pandemia e o fechamento de escolas ainda não geraram um número suficiente de estudos nacionais e internacionais para sustentar um estado da arte consistente sobre o tema.

Diante do exposto, o presente estudo teve como objetivo investigar os desafios da relação escola-família na pandemia da COVID-19 e no ensino remoto emergencial, por meio da percepção dos professores da educação básica de escolas localizadas no Estado do Rio de Janeiro. Espera-se que os resultados da pesquisa possam contribuir para o campo científico, político e prático nos processos pedagógicos. Ademais, possa suscitar o interesse de educadores na defesa de programas com evidências na formação inicial e continuada de profissionais de educação, consolidar práticas positivas de relacionamento entre a escola e família em prol do aluno. A seguir, será apresentado o método utilizado nesta pesquisa e os resultados gerados com a finalidade de propiciar reflexões mais aprofundadas a respeito do tema dessa investigação.

\section{Metodologia}

Para a realização dessa pesquisa adotou-se uma abordagem exploratório-descritiva de natureza qualitativa. A perspectiva temporal de análise foi transversal (Neuman, 2014), com corte temporal, no período de maio a agosto de 2020 , quando foi realizada a coleta de dados 


\subsection{Participantes}

A amostra contou com 106 professores da educação básica que atuam em escolas do Estado do Rio de Janeiro com as infâncias, nos segmentos referentes à Educação Infantil e ao Ensino Fundamental I (50,9\%) e com as adolescências, nos segmentos referentes aos Ensino Fundamental II e Médio (49,1\%). O grupo era composto majoritariamente por mulheres (83\%), com idades em torno de 43 anos $(M=32 ; D P=12)$, que se autodeclararam brancas $(52,8)$, pardas e negras $(46,2 \%)$, casadas ou em união estável (66\%), com filhos $(74 \%)$ e religiosas $(73,6 \%)$. No que tange à qualificação profissional, a maioria dos participantes tinha especialização (50,9\%), enquanto outros, eram mestres e doutores (29,2\%). A maioria tinha mais de 10 anos de profissão (75\%) e trabalhava em escola pública municipal, estadual ou federal (74,5\%).

\subsection{Procedimentos éticos e de coleta de dados}

A pesquisa foi aprovada por um comitê de ética (CAAE: 17070619.2.0000.5289). Os dados foram coletados por meio de um formulário eletrônico autopreenchido, disponibilizado pela plataforma Google Forms. A amostragem foi por conveniência, logo, não probabilística e não representativa da população. Para minimizar problemas relacionados ao tipo adotado de amostragem da pesquisa foram utilizados diferentes canais de divulgação, como: Facebook, Instagran, Whatsapp, Email. O período de coleta de dados foi de 22 de maio ao dia 08 de agosto de 2020, permitindo que os professores pudessem relatar suas experiências preliminares sobre a pandemia COVID-19 e as experiências com o ensino remoto emergencial. Seguindo as orientações do Ofício Circular n²/2021/CONEP/SECNS/MS que trata das orientações para procedimentos em pesquisas com qualquer etapa em ambiente virtual, todos os participantes foram informados sobre os objetivos da pesquisa. Ademais, foi incluso no formulário enviado o Termo de Consentimento Livre e Esclarecido para a devida concordância do participante.

\subsection{Instrumentos}

Foram utilizados dois instrumentos de coleta: (i) a Escala Relação Família Escola (RFE), adaptada e abreviada para a pesquisa, e (ii) um questionário sobre os indicadores sociodemográficos-laborais e uma pergunta aberta específica sobre os desafios da relação escola família na pandemia. A escala RFE (Saraiva-Junges \& Wagner, 2015) é originalmente composta por 69 itens e distribuídos em sete fatores. A saber: 1. Escolha Profissional (EP); 2. Formação Acadêmica (FA); 3. Satisfação com o trabalho (ST); 4. Apoio da Escola (AE),5; Demandas advindas das Famílias dos alunos (DF); 6. Visão dos professores sobre as Famílias (VF); 7. Comunicação com as Famílias (CF). Os itens são respondidos em uma escala Likert com seis opções de respostas, variando de 1(Discordo Totalmente) a 6 (Concordo Plenamente). Para o presente estudo, foram utilizados apenas 28 itens referentes ao foco desse estudo. As adaptações e abreviações da escala são de responsabilidades das autoras desta pesquisa, por considerarem não haver comprometimento com a integralidade do instrumento. Seguem exemplos de itens utilizados para cada dimensão da escala: (EP) "Ser professor para mim não foi uma opção, mas uma convicção.” (FA) "Na minha formação docente não tive disciplinas que abordassem temas relacionados ao trato com as famílias dos alunos." (ST) "Penso que mesmo com a responsabilidade de influenciar e educar as futuras gerações, nós, professores, somos pouco valorizados." (AE) "A ausência de setores de apoio aos professores nos deixa na linha de frente, suscetíveis a críticas das famílias." (DF) "Muitas famílias delegam todos os cuidados com os filhos a mim e à escola." (VF) "Penso que o ambiente familiar é responsável por muitos dos problemas que os alunos apresentam." (CF) "Relaciono-me com famílias de meus alunos sempre formalmente, seja em reuniões de pais ou entrevistas marcadas." A pergunta aberta do questionário foi a seguinte: "Para você, quais são os principais desafios que a pandemia vem trazendo para a relação entre escola e as famílias dos alunos?". 


\subsection{Procedimentos de análise de dados}

Os dados dos indicadores sociodemográficos-laborais foram analisados com auxílio do software SPSS 22.0. Em seguida, para análise das respostas da escala RFE, os dados foram separados e organizados mediante tabulação em planilhas do programa Microsoft Office Excel® 2016 e submetidos à análise no Software para Análise Estatística para Ciências Sociais Rstudio ${ }^{\circledR}$ que tem interface com R 4.4.1. Por fim, as respostas da referida questão aberta foram organizadas em uma planilha do Microsoft Office Excel ${ }^{\circledR}$, analisadas e agrupadas por similaridade semântica, atribuídas pelos pesquisadores. A partir desses agrupamentos, foram criados temas e subtemas que foram nomeados com base na Teoria Bioecológica, que interferiu diretamente na apresentação dos resultados. O processo de análise foi inspirado nos princípios metodológicos da Grounded Theory (Charmaz, 2009). Os participantes foram codificados pelo segmento de ensino: EI (Educação Infantil); FI (Ensino Fundamental I); FII (Ensino Fundamental II); EM (Ensino Médio). Exemplificando P(1)-EI.

\section{Resultados}

As respostas dos professores referentes a propriedade de boas relações entre escola e as famílias resultaram em 100\% de concordância sobre os benefícios para o aluno em suas tarefas de aprendizagem. A maioria dos educadores (96\%) revelou estar disponível e aberto para dialogar com as famílias de seus alunos a qualquer momento. No entanto, concordaram (77\%) que os horários de trabalho são inconciliáveis entre a escola e as famílias, prejudicando a comunicação direta com os pais. Verificou-se ainda que 58\% dos educadores (92\%) achavam sempre mais fácil e prático se comunicar com as famílias por meio de bilhetes, agenda, circulares e e-mail. Pode-se apurar que 58\% dos professores concordaram que se relacionam com as famílias dos alunos sempre formalmente, seja em reuniões de pais ou entrevistas marcadas. Segue abaixo a Figura 1 com o gráfico produzido com o sumário das respostas e respectivos valores em percentual apurados.

Figura 1: Resultados gerais escala RFE.

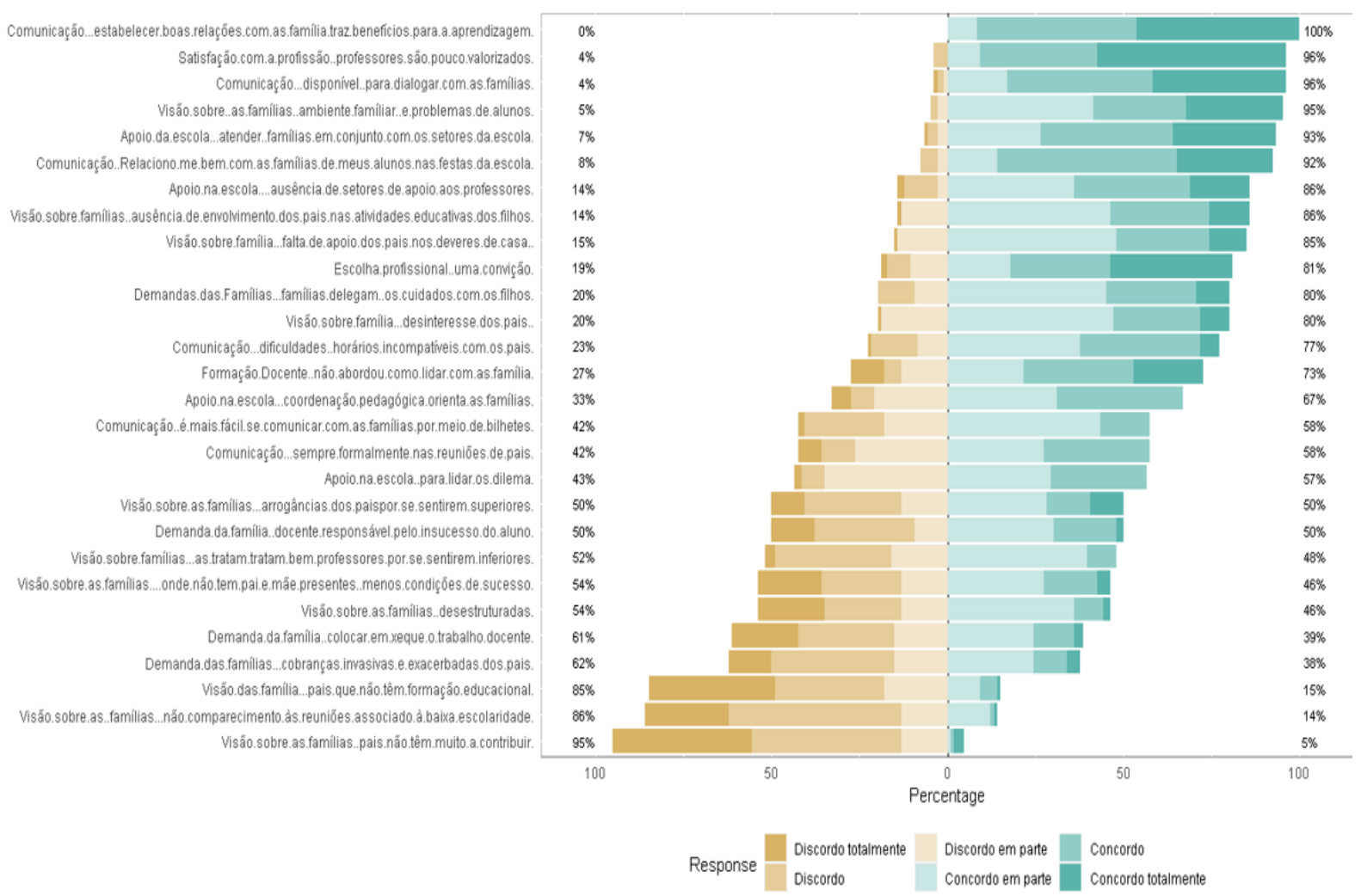

Fonte: Autores. 
Nota. Resultado gráfico obtido do Software para Análise Estatística para Ciências Sociais Rstudio® com interface com R 4.4.1., das respostas relacionadas aos 28 itens retirados da escala Relação Família Escola (RFE).

Constatou-se que $80 \%$ dos profissionais concordaram que muitas famílias delegavam a eles e à escola todos os cuidados educacionais de seus filhos. Metade do grupo participante concordou que é comum as famílias responsabilizarem o professor pelo insucesso do aluno. Todavia, $61 \%$ dos participantes discordaram que as famílias costumam colocar em xeque seu trabalho docente. Verificou-se que $62 \%$ dos professores discordaram que no seu dia-a-dia receberam cobranças invasivas e exacerbadas dos pais que queriam ser atendidos em todas as suas demandas sem se submeter a organização maior da instituição.

Constatou-se que a maioria dos professores (93\%) sentiu segurança em atender famílias em conjunto com os setores de apoio da sua escola. Entretanto, $86 \%$ se queixaram da ausência de apoio aos professores, deixando-os na linha de frente, suscetíveis a críticas das famílias. Pode-se notar que $67 \%$ dos professores contaram com uma coordenação pedagógica que orienta as famílias dos alunos e $57 \%$ sentiram-se apoiados pela instituição para lidar com os dilemas. da sua prática cotidiana.

Verificou-se que $95 \%$ dos participantes pensam que o ambiente familiar é responsável por muitos problemas que os alunos apresentam na escolarização. Pôde-se também conferir que $86 \%$ percebem ausência de envolvimento dos pais nas atividades que envolviam seus filhos (tema de casa, reuniões de pais, auxílio nos estudos e na organização do material, entre outros). Nesse contexto, $85 \%$ dos professores concordam com a falta de apoio dos pais na realização dos deveres escolares de seus filhos, enquanto $80 \%$ sugerem desinteresse dos pais nas atividades educativas.

Ademais, os resultados mostraram que um pouco mais da metade (54\%) dos participantes discordou da proposição de que crianças e adolescentes provenientes de lares que não têm pai e mãe presentes tem menos condições de se saírem bem na escola. Os dados percentuais coincidiram com o anterior no que tange à discordância com o termo família desestruturada atribuído usualmente às diferentes configurações familiares que se afastam do modelo idealizado de família tradicional. Podese também apurar que 54\% dos professores discordaram da percepção das famílias como desestruturadas, devido a serem configuradas por mães solteiras, pais separados, avós que cuidam dos netos, entre outros. A maioria (85\%) discordou da ideia de que pais que não tem formação educacional não tem muito a contribuir com o currículo escolar. Constatou-se que $86 \%$ dos professores discordaram da ideia de que os pais que não compareciam as reuniões e atividades promovidas pela escola eram aqueles que possuíam baixa escolaridade. A maioria (95\%) discordou que, em geral, as famílias não tem muito a contribuir com a atividade do professor.

Verificou-se que $73 \%$ dos professores não tiveram no curso de graduação disciplinas específicas relacionadas ao trato com as famílias dos alunos. Verificou-se também que a escolha da profissão, para a maioria dos professores (81\%) não foi uma opção, mas uma convicção. Certificou-se, no entanto, que os professores ressentem a falta de valorização da profissão, pois $96 \%$ participantes concordaram que mesmo com a responsabilidade de influenciar e educar as futuras gerações, os professores são pouco valorizados.

No que se refere aos resultados obtidos acerca dos principais desafios que o isolamento social impôs à relação escolafamílias, identificamos quatro dimensões: (1) macrossistêmica, (2) mesossistêmica, (3) microssistêmica e (4) cronossistêmica. Os agrupamentos seguiram os níveis ecológicos de desenvolvimento, evidenciando a interconectividade entre os contextos (Bronfenbrenner \& Morris, 1998), sugerindo uma visão sistêmica da relação escola-família. A síntese dos resultados das análises está apresentada na Tabela 1. 


\section{Organização das respostas do questionário}

Tabela 1: Resultados das respostas da questão aberta: "Para você, quais são os principais desafios que a pandemia vem trazendo para a relação entre escola e as famílias dos alunos?"

\begin{tabular}{|c|c|c|c|}
\hline Dimensões & Categorias & Subcategorias & $\%$ \\
\hline Macrossistêmica & $\begin{array}{c}\text { Desigualdade social } \\
\text { isolamento social diferenças } \\
\text { sociais e econômicas }\end{array}$ & $\begin{array}{c}\text { Desafios relacionados às } \\
\text { injustiças e desigualdades } \\
\text { sociais }\end{array}$ & 22,6 \\
\hline Mesossistêmica & $\begin{array}{c}\text { Família-escola } \\
\text { professor-aluno } \\
\text { comunidade-famílias-escolas }\end{array}$ & $\begin{array}{c}\text { Desafios relacionados aos } \\
\text { processos de comunicação }\end{array}$ & 40,5 \\
\hline Microssistêmica & $\begin{array}{c}\text { Pais e filhos } \\
\text { professora aluno } \\
\text { Professor família }\end{array}$ & $\begin{array}{c}\text { Desafios relacionados aos } \\
\text { processos proximais }\end{array}$ & 29,4 \\
\hline Cronossistêmica & Tempo histórico de & $\begin{array}{c}\text { Desafios relacionados aos } \\
\text { fatores de risco à saúde } \\
\text { emocional }\end{array}$ & 7,5 \\
\hline
\end{tabular}

Fonte: Autores.

Nota. Resultados obtidos a partir das análises das respostas considerando as semelhanças e similitudes de sentidos e significados, sob inspiração dos princípios metodológicos da Grounded Theory.

A dimensão mesossistêmica representou 40,5\% das respostas referentes às relações entre família escola, professora aluno, comunidade-família-escola. Tal contexto aponta para os desafios relacionados aos processos de comunicação. Seguem exemplos de relatos das participantes quanto aos desafios: "Comunicação eficiente e atender às sugestões de todos os pais” (P95-EM). “A falta de diálogo” (P83-FII) “Acho que as escolas estão com muita dificuldade em levantar as principais demandas das famílias, falta escuta, a escola só comunica. Fica um vazio, um distanciamento muito grande. Fica faltando acolhimento, tão importante nesse momento” P15-EI). “A falta de contato físico aumenta o afastamento” (P.21-PI). "Muitas famílias não procuram entrar em contato com a escola para saber o que seria feito durante a quarente. Então elas acabam não tendo conhecimento das atividades que estão senso desenvolvidas por nós (P.96-EM).

A dimensão microssistêmica representou $29,4 \%$ das respostas referentes às relações entre pais e filhos, professor e aluno, professor e pais. Tal contexto aponta para os desafios relacionados aos processos proximais. Seguem exemplos de relatos das participantes quanto aos desafios: "Exatamente a relação professor e aluno. Transmissão de conhecimento em tempo real via internet e a aprendizagem do aluno comprometido em casa, devido a troca de experiência como era de costume” (P.4-EI). "O distanciamento esfria as relações e nos afasta uns dos outros por mais que tentamos nos 'aproximar” (P.38-FI). “Criar uma nova forma de ensinar” (P.86-FII). “Os alunos não se comprometem com o estudo” (P.106-EM).

A dimensão macrossistêmica representou 22,6\% das respostas referentes à desigualdade social, isolamento social, diferenças sociais e econômicas. Tal contexto aponta para os desafios relacionados às injustiças e desigualdades sociais que interferem nos processos proximais. Seguem exemplos de relatos das participantes quanto aos desafios: "O maior desafio é a fome” (P.37-FI). "Muitas famílias não possuem acesso à internet para que os filhos participem de atividades remotas que as escolas oferecem" (P.41-FI). "A desigualdade social, pois muitos dos meus pequenos não têm internet, a falta de um adulto em horário integral, pois muitos pais continuam a trabalhar e deixam as crianças com parentes, vizinhos ou em crecheiras, aquela tia da comunidade que presta serviço a essas pessoas" (P.1-EI). "A falta de acesso aos meios tecnológicos impede que haja qualquer relação entre os envolvidos" (P.84-FII).

A dimensão cronossistêmica representou 7,5\% das respostas referentes ao tempo de pandemia e ao ensino remoto decorrente. Tal contexto aponta para os desafios relacionados aos fatores de risco à saúde emocional. Seguem exemplos de 
relatos das participantes quanto aos desafios: "Acredito que o psicológico seja o lado mais afetado de ambos os lados" (P.109EM). "Os pais não têm paciência e nem tempo para auxiliar nas tarefas e isso gera brigas. Complicado, mas é preciso pôr tudo na balança" (P.50-FI). "Manter uma comunicação clara e dar atenção também aos aspectos emocionais tanto aos pais quanto aos alunos." "Há vários relatos de ansiedade e depressão" (P.103-EM).

Embora a pesquisa esteja relacionada aos desafios da relação escola família nesse período de pandemia e de ensino remoto, uma pequena parte dos professores (cerca de 5\%) vislumbrou espontaneamente as possibilidades de transformações positivas em meio ao momento social instaurado pelo fenômeno pandêmico. Nesse sentido, verificou-se o sentimento de esperança em dias melhores. Esse grupo de respostas foi categorizado como a possibilidade de haver alguma luz no fim do túnel. Seguem exemplos de relatos: "Acredito que vem nascendo um olhar sistêmico da escola para o aluno. Não quero dizer que o professor se veja como tutor da família, mas com pouco mais de compreensão sobre a cultura do aluno" (P.101-EM). "A disponibilidade tem sido maior, pois há horários definidos para a recebimento de mensagens e o atendimento é individual e diário, com maior frequência do que quando ocorrem as aulas presenciais" (P.25-PI).

\section{Discussão}

O presente estudo teve como objetivo investigar os desafios da relação escola família durante a pandemia da COVID19 e do ensino remoto emergencial. Buscou-se conhecer a percepção dos professores da educação básica a partir das lentes da TBDH (Bronfenbrenner \& Morris, 1998). Para tanto, foram trazidas discussões conceituais e dados empíricos acerca do tema como contributo significativo para a compreensão das práticas relacionais cotidianas desse importante mesossistema no desenvolvimento de escolares. Nesse contexto, pode-se dizer que o objetivo do estudo foi alcançado e ampliado.

Inicialmente, podemos afirmar que os resultados das análises deste estudo mostraram uma configuração muito positiva de professores no que se refere aos benefícios da relação entre a escola e a família para o desenvolvimento dos estudantes, corroborando com as pesquisas nesse campo do conhecimento (Epstein, 1986, 1987, 2011,2018; Hornby \& Lafaele, 2011; Sheridan, 2018; Wagner et al., 2019; Willemse et al.,2018). Poder-se ia sugerir que a potência da unanimidade do resultado pode ser reflexo de uma maior sensibilidade dos professores trazida pela proximidade dos mesmos com a realidade vivida por seus alunos durante a pandemia (Ferrara et al., 2021; Magalhães et al.,2021; Richmond et al.,2020). Foi verificado ainda a disponibilidade dos professores para o diálogo com as famílias, contradizendo as atribulações e impasses na comunicabilidade encontrados por Glidden (2018) ao pesquisar os desafios da comunicação entre a família e escola na literatura científica.

Todavia, mesmo considerando o caráter favorável e a disponibilidade dialógica dos professores em relação às famílias, os resultados apontam que coexiste um clima de insegurança dos profissionais em atender sozinhos alguns familiares. Estes profissionais já afirmam estar mais seguros em atendimentos conjuntos com as equipes de apoio da escola. Isso pode ser entendido como falta de embasamento teórico pela lacuna existente na formação do professor no que tange às disciplinas relacionadas ao trato com as famílias, o que corrobora com os estudos de Epstein (2018). De fato, as pesquisas realizadas pela autora reiteram a importância de preparo de educadores para minimizar essa sensação de insegurança, e às vezes até impotência, no trato com as famílias, por meio de um currículo que atenda às necessidades básicas sobre os processos de relacionamento entre escola-família-comunidade.

Vale destacar que as análises dos dados, evidenciaram a desconfiança dos professores no que diz respeito aos cuidados dos pais com os filhos, e a culpabilização das famílias ao atribuir responsabilidade às mesmas pelos problemas que os alunos apresentam, conforme explicitado em pesquisas prévias (Patto, 1990; Polonia \& Dessen, 2005; Saraiva-Jungles \& Wagner, 2013; Yunes \& Szymanski, 2003; Yunes et al., 2007). Com efeito, podemos afirmar que pouco se modificou a impressão dos professores sobre as famílias, especialmente das classes populares, constituída na maioria de pretos 
(Patto,1990). Tais concepções de educadores foram historicamente produzidas ainda nos primórdios da democratização do ensino educação das classes populares, no século XIX e ampliadas nos idos de 1960 (Pranto,2020).

Decerto que já se verificam avanços, quando se verifica que a maioria dos professores não considera que a condição de crianças e adolescentes provenientes de lares onde a família não tem pais presentes seja um obstáculo para desenvolvimento escolar. Reiteramos que esse resultado é um ponto surpreendente, dado que a literatura demonstra o oposto (Patto, 1990; Polonia \& Dessen, 2005; Saraiva-Jungles \& Wagner, 2013; Yunes \& Szymanski, 2003; Yunes et al., 2007). Todavia, no que corresponde à visão de família "desestruturada" dirigida aos grupos com diferentes configurações familiares, os professores se dividiram: 54\% não concordam com essa classificação, enquanto o restante do grupo concorda. Esse resultado se aproxima dos resultados de estudos anteriores (Saraiva-Jungles \& Wagner, 2013; Yunes \& Szymanski, 2003; Yunes et al., 2007) e é preocupante que se mantenham em proporções significativas ao longo de décadas. É de referir que os professores discordaram majoritariamente da ideia de que pais que não têm formação educacional não estão capacitados a contribuir com o currículo escolar. Portanto, observamos que esse grupo de participantes tende a ter um olhar menos preconceituoso e mais empático com as famílias de seus alunos quando comparado às pesquisas anteriores (Yunes \& Szymanski, 2003; Yunes et al., 2007).

No que se refere às análises dos resultados relativos aos desafios da relação escola família, no período inicial da pandemia, as ferramentas conceituais da TBDH (Bronfenbrenner \& Morris, 1998) subsidiaram nossa compreensão sobre o fenômeno. A partir desses parâmetros, identificamos padrões correspondentes aos ecossistemas (Bronfenbrenner \& Morris, 1998): (i) macrossistêmico (desigualdade social, isolamento social, diferenças sociais e econômicas); (ii) mesossistêmico (família-escola, professor-aluno, comunidade-famílias-escola); (iii) microssistêmico (relações proximais entre pais e filhos; professor-aluno); (iv) cronossistêmico (tempo de pandemia).

Assim, os desafios percebidos com maior frequência remetem às questões coletivas e relacionais, dando ênfase às barreiras nos processos de comunicação entre a escola e a família. Outros desafios relacionais não menos importantes, mas com menor incidência estão na esteira dos processos proximais entre pais e professores, pais e alunos e professores e alunos e às injustiças e desigualdades sociais das famílias. Por fim, desafios com ênfase em processos mais subjetivos e individuais aparecem com temas ligados aos fatores de risco à saúde emocional das pessoas da comunidade escolar.

Embora o grupo de professores participantes deste estudo não tenham dado ênfase ao impacto individual e coletivo socioemocional no período inicial da pandemia, outros trabalhos evidenciaram esse aspecto com maior prevalência, com destaque aos impactos geracionais a longo prazo (Fonseca et al., 2020; Rogers et al., 2021). Assim como a amplificação dos problemas psicológicos em crianças que vivem em ambientes domésticos estressantes (Moroni, Nicoletti \& Tominey, 2020). Neste trabalho, o grupo investigado focou em questões mais pragmáticas, provavelmente em função do período no qual os dados foram coletados, quando professores ainda experienciavam o início do ensino remoto.

Quanto às possibilidades, foram menos referidas pelos professores, mas também identificadas, como na expressão "há alguma luz no fim do túnel". Destaca-se que a esperança de dias melhores pode reconstruir e ressignificar situações de risco e descrença. Outro grande desafio está relacionado a falta de contato presencial, o "cara a cara" o "olho no olho" do professor com o aluno. Segundo Bronfenbrenner e Ceci (1994) o desenvolvimento humano se dá nas relações proximais, face a face, e é esse o motor primário de desenvolvimento. Na relação proximal, as capacidades biológicas e o potencial genético de cada pessoa quando estimulado, potencializa os recursos pessoais. Assim, o processo de aprendizagem se estabelece no engajamento, na regularidade e no tempo, seguindo uma hierarquia do mais simples ao complexo, embalada pelo envolvimento afetivo. Todavia, as condições de aprendizagem, na modalidade remota emergencial, parecem exigir outras competências e habilidades. Ainda que os estudos sejam ainda preliminares, já apontam que a modalidade remota de ensino gerou dificuldades emocionais e relacionais (Crescenza et al.,2021) e, sobretudo, a incapacidade de atender a todos (Hetkwoski et al., 2020). 
Outro desafio identificado nas análises, porém, com menor frequência, se refere à pobreza, às injustiças e às desigualdades sociais das famílias. Lamentavelmente, essa é uma situação crônica no território brasileiro, conforme indicam alguns pensadores que se dedicaram aos estudos da exclusão e pobreza no Brasil (Algebaille, 2009; Patto,1990). Decerto que os resultados das análises espelham essa posição nas denúncias de professores, quando apontam a fome, a falta de recursos tecnológicos para acompanhar às aulas online, a exclusão e o abandono. Essa realidade de escassez e privações corrobora as pesquisas atuais quando atestam que alunos em condição de vulnerabilidade não tinham computadores funcionando ou acesso adequado à Internet em casa e não podiam participar do aprendizado online (Bozkut et al., 2020; Epstein, 2020). Concordamos com Magalhães (2021) quando afirma que o ensino remoto contribuiu para escancarar as desigualdades na realidade dos estudantes brasileiros, violando o direito constitucional à educação (p.3).

Por fim, podemos inferir que a pandemia causou estranhamentos e desnaturalização das realidades famílias dos alunos, assim como o uso das tecnologias digitais como suporte do ensino remoto emergencial transformou as práticas docentes. Vale refletir sobre as formas tradicionais de transmissão do conhecimento e do saber nas escolas que se manifestam por meio de ideologias valorizadas pela sociedade, e ensinados e aprendidos por meio do currículo estabelecido (Apple, 2018). A pandemia está oportunizando outras formas de contato, ou seja, os professores e os formadores de professores estão conhecendo as casas e as comunidades dos alunos (Richmand, 2020). Podemos, supor que os achados positivos encontrados se devem ao olhar sensibilizado dos professores às privações das famílias e consequentemente dos alunos, ao distanciamento social e a implementação do ensino remoto. Consideramos também, que a necessidade de superar as dificuldades com o uso das tecnologias digitais, para fins pedagógicos, pode ter desenvolvido processos de empatia dos professores voltados aos alunos e suas respectivas famílias.

\section{Considerações Finais}

Embora ainda não tenhamos um volume de produções científicas suficientes que sustentem afirmações mais robustas para compreender os efeitos da pandemia e do ensino remoto na relação escola-família, já podemos refletir sobre políticas reorganizadoras de práticas que incentivem o relacionamento entre os profissionais de educação e as famílias. Especialmente porque na percepção docente a parceria entre a escola e a família é essencial para o desenvolvimento saudável e o sucesso escolar de crianças e adolescentes.

Vale destacar que estamos alinhadas à perspectiva da Psicologia Social Comunitária que estuda a relação com base nas demandas, respeitando os princípios éticos em prol da dignidade humana, da Psicologia Social Comunitária que estuda a relação com base nas demandas, respeitando os princípios éticos em prol da dignidade humana, da qualidade de vida, sem perder de vista as injustiças e as desigualdades sociais (Maciel \& Barbosa, 2015). Nessa orientação, a realidade escolar deve ser enfrentada com ações e propostas de formulação de políticas de apoio que defendam uma educação pública de qualidade para todos, garantindo, assim, os direitos constitucionais (Conceição \& Zamora, 2015).

Deve-se ressaltar que assim como Bronfenbrenner (2011), consideramos fundamental fomentar políticas públicas para o bem-estar e desenvolvimento dos seres humanos em diferentes contextos. Assim, nosso intento é fornecer subsídios na construção de parcerias ativas e colaboradoras entre a escola e a família em prol do sucesso do aluno. À vista disso, se faz necessário que outros estudos continuem a investigar a temática, contribuindo com ações que favoreçam os encontros, parcerias e colaboração entre os atores da comunidade escolar. Além disso, sugere-se a realização de estudos de programas com evidências para auxiliar a formação da comunidade escolar, para compreender e aprimorar o trato interpessoal dos/as agentes escolares do seu entorno/contexto e de sua base local. 
Este estudo teve algumas limitações, tanto no que se refere à natureza transversal que não permitiu o acesso direto aos desafios de superação apresentados ao longo do tempo, quanto não ter acesso a outros atores da comunidade escolar, como as famílias e alunos. Além disso, a utilização de instrumentos de autorrelato pode levar a respostas socialmente desejáveis.

Ademais, levando em consideração o ineditismo do fenômeno na atual situação sanitária mundial, faz-se necessário que pesquisadores e governantes possam seguir monitorando os impactos da pandemia daqui para frente. A despeito do fortalecimento da educação para crianças e adolescentes, durante e pós pandemia, é importante investir em programas de formação referentes à escola-família, como parte constitutiva do exercício profissional do professor.

Por fim, esperamos que esta pesquisa possa servir como ponto de partida para outras pesquisas a serem desenvolvidas no território brasileiro, no campo do desenvolvimento relacional positivo entre a escola e as famílias, a fim de beneficiar os estudantes nesse momento crítico que foge o controle, ante as consequências desse devir. À vista disso, além de compreender os benefícios dos processos proximais e das competências digitais na relação escola-família, precisamos garantir uma educação igualitária para todos.

\section{Agradecimentos}

O presente estudo contou com o apoio dos professores do ensino básico que, mesmo com tantos desafios impostos pela pandemia COVID-19, dedicaram parte do seu tempo a contribuir com a pesquisa.

\section{Referências}

Algebaile L. E. (2009). Escola pública e pobreza no Brasil: a ampliação para menos. Lamparina,

Apple, M. W. (2018). Ideology and cultural and economic reproduction. In Ideology and curriculum, 26-44. Routledge.

Antunes, A. (2016). O Conselho de Escola, a Associação de Pais e Mestres e o Grêmio Estudantil como espaços de exercício de cidadania participativa. Parlamento e Sociedade, 4 (6), 99-122. Versão eletrônica: www.camara.sp.gov.br

Bhering, E., \& Siraj-Blatchford, I. (1999). A relação escola-pais: um modelo de trocas e colaboração. Cadernos de pesquisa, 106, 191-216. https://doi.org/10.1590/S0100-15741999000100010

Bozkurt, A. et al. (2020). A global outlook to the interruption of education due to COVID-19 pandemic: Navigating in a time of uncertainty and crisis. Asian Journal of Distance Education. 15(1), 1. URI:10.5281/zenodo.3878571

Bronfenbrenner, U.\& Ceci, S. J. (1994) Nature-nuture reconceptualized in developmental perspective: A bioecological model. Psychological review. 101(4), 568 .

Bronfenbrenner, U. (1994). Ecological models of human development. In T. Husen \& T. N. Postlethwaite (Eds.). International Encyclopedia of Education. 3 (2a ed) 1643-1647). Oxford, England: Pergamon Press/Elsevier Science.

Bronfenbrenner, U. (1996). A ecologia do desenvolvimento humano: experimentos naturais e planejados. Porto Alegre: Artmed.

Bronfenbrenner, U. (2011) Bioecologia do desenvolvimento humano: Tornando os seres humanos mais humanos. Porto Alegre: Artmed.

Bronfenbrenner, U., \& Morris, P. A, (1998).The ecology of development processes. In Damon, W (Series Ed.) \& R. M. Lerner (Vol. Ed). Handbook of child psychology: 1. Theoretical models of human development, 993-102.Wiley.

Bronfenbrenner, U. \& Evans, G. W. (2000). Developmental science in the 21 st century: emerging questions, theoretical models, research designs and empirical findings. Social Development, 9(1), 115-125.

Buza, V.\& Hysa, M. (2020) School-family cooperation through different forms of communication in schools during the Covid-19 pandemic. Thesis. 9 (2), 55-80. https://doi.org/hrcak.srce.hr/250874

Cárceres-Muños, Jiménez-Hernandes, A.S., Martín-Sánchez, M. (2020). Cierre de escuelas y desigualdad socioeducativa en tiempos del Covid-19. una investigación exploratoria en clave internacional. Revista Internacional de Educación para la Justicia Social. 9 (3), 199-221.https://doi.org/10.15366/ riejs 2020.9.3.011

Carvalho, L. de O., \& Feldens, D.G. (2020) Ensaios de desfazimento e clamores por ordenamento: uma reflexão sobre o tensionamento moral entre a escola e a família. Revista Cocar, 14(30). https://periodicos. uepa.br/ index.php/cocar/article/ view/3482

Charmaz, K. (2009). A construção da teoria fundamentada: guia prático para análise qualitativa. Porto Artmed.

Cluver, L.; Lachman, J.M.; Sherr, L.; Wessels, I.; Krug, E.; Rakotomalala,S. ; Blight, S.; Hillis, S. ; Bachman, G.; Green,O.; Butchart, A.; Tomlinson, M.; Ward, C.L.; Doubt, J.; McDonald,K., (2020). Parenting in a time of COVID-19. Lancet, 395 (10231). https://doi: 10.1016/ S 0140-6736(20)30736-4 
Conceição, V. L. D., \& Zamora, M. H. R. N. (2015). Desigualdade social na escola. Estudos de Psicologia (Campinas), 32, 705-714. https://doi.org/10.1590/0103-166X2015000400013

Crescenza, G., Fiorucci, M., Rossiello, M. C., \& Stillo, L. (2021). Education and the pandemic: Distance learning and the school-family relationship. Research in Education and Learning Innovation Archives, 26, 73-85. https://doi.org/ 10.7203/realia. 26.18078

Dessen, M. A., \& Polonia, A. D. C. (2007). A família e a escola como contextos de desenvolvimento humano. Paidéia (Ribeirão Preto);17, 21-32. https://doi.org/10.1590/S0103-863X2007000100003

Epstein, J. (1986). Parents' reactions to teacher practices of parental involvement. The Elementary School Journal, 86, 277-294. https://www.journals.uchicago.edu/doi/abs/10.1086/461449

Epstein, J. L. (2018). School, family, and community partnerships: Preparing educators and improving schools. Routledge.

Epstein, J. L. (2020). Partnerships Keep Children Learning During COVID-19. Contexts, 19(4), 88-90. https://doi.org/10.1177/1536504220977949

Faria, J. H. D., \& Meneghetti, F. K. (2011). Burocracia como organização, poder e controle. Revista de Administração de Empresas, 51,424-439. https://doi.org/10.1590/S0034-75902011000500002.

Fonseca, R. P., Sganzerla, G. C., \& Enéas, L. V. (2020). Fechamento das escolas na pandemia de Covid-19: Impacto socioemocional, cognitivo e de aprendizagem. Debates Em Psiquiatria,10(4), 28-37. https://doi.org/10.25118/2763-9037.2020.v10.23

Gârţu, M. L. (2017). The school-family educational partnership. Journal of Pedagogy, 2, 107-123. https://doi.org/10.26755/ RevPed/2017.2/107

Glidden, R. F. (2018). Comunicação família e escola: Tensões e desafios. Revista da Faculdade de Educação da Universidade do Estado de Mato Grosso, 29(16), 159-175. http://doi.org/10.30681/21787476.2018.29.159174.

Hetkowski, T. M.; Nascimento, F. dos S.; Araújo, K. S. S. (2020) Emergency Remote Teaching (ERT): Reflexões sobre trabalho pedagógico e uso das TIC na rede pública municipal. Linguagens, Educação e Sociedade, 25(46), 194-198. https:// doi.org: 10.26694/les. v0i46.11444

Hornby, G., \& Lafaele, R. (2011). Barriers to parental involvement in education: An explanatory model. Educational Review, 63(1), 37-52. https://doi.org/10.1080/00131911.2010.488049

Lee, R. E. (2018). Breaking down barriers and building bridges: Transformative practices in community- and school-based urban teacher preparation. Journal of Teacher Education, 69(2),118-126. https://doi.org/10.1177/0022487117751127

Lima, A. M., \& Machado, L. B. (2020) Um estudo sobre famílias de alunos de escola pública nas representações sociais construídas por docentes. Revista Diálogo Educacional, 20 (66), 1332-1356. http://dx.doi.org/10.7213/1981-416X.20.066.DS17

Magalhães, R. C. D. S. (2021). Pandemia de covid-19, ensino remoto e a potencialização das desigualdades educacionais. História, Ciências, SaúdeManguinhos, 28 (4), 1263-1267. https://doi.org/10.1590/S0104-59702021005000012

Maciel, T. M. de F. B., \& Alves, M. B. (2015). A importância da psicologia social comunitária para o desenvolvimento sustentável. Pesquisas e Práticas Psicossociais,10(2), 272-282. http://pepsic.bvsalud.org/scielo.php?script=sci_arttext\&pid=S1809-89082015000200005\&lng=pt\&tlng=pt

Matos, L. A., Cruz, E. J. S. D., Santos, T. M. D., \& Silva, S. S. C. (2018). Resiliência Familiar: o olhar de professores sobre famílias pobres. Psicologia Escolar e Educacional, 22, 493-501.https://doi.org/10.1590/2175-35392018038602

Melo, S. C.de, Santos, M. P. dos, Loureiro, C. R. N. da S., \& Calvente, A. (2017). Racismo e Educação Escolar: reflexões sobre o lugar do aluno negro. Revista de Educação PUC-Campinas, 22(1), 93-107. https://doi.org/10.24220/P1519-3993-2017220100007

Moroni, G., Nicoletti, C., \& Tominey, E. (2020). Children's socio-emotional skills and the home environment during the COVID-19 crisis. CEPR VoxEu. https://voxeu.org/article/children-s-socio-emotional-skills-and-home-environment-during-covid-19-crisis

Moura, G. G.; Nascimento, C. R. R.\& Ferreira, J. M. (2020) COVID-19: Reflections on the Crisis, Transformation, and Interactive Processes Under Development. Trends in Psychology, 1-20. https://doi.org/10.1007/s43076-020-00061-z

Neuman, D. (2014). Qualitative research in educational communications and technology: a brief introduction to principles and procedures. $J$ Comput High Educ, 26,69-86. https://doi.org/10.1007/s12528-014-9078-x

Nonato, Yunes \& Carvalho (no prelo). Teorias implícitas de profissionais da educação sobre crianças, adolescentes e famílias em situação de pobreza (no prelo). Gerais: Revista Interinstitucional de Psicologia.

Patto, M. H. de S. (2000). A produção do fracasso escolar: histórias de submissão e rebeldia. Casa do Psicólogo.

Pisano, L., Galimi, D., \& Cerniglia, L. (2020). A qualitative report on exploratory data on the possible emotional/behavioral correlates of Covid-19 lockdown in 4-10 years children in Italy.PsyArXiv. https://doi.org/10.31234/osf.io/stwbn

Polonia, A. D. C., \& Dessen, M. A. (2005). Em busca de uma compreensão das relações entre família escola. Psicologia escolar e educacional, 9(2), 303-312. https://doi.org/10.1590/S1413-85572005000200012

Richmond, G. (2017). The power of community partnership in the preparation of teachers. Journal of Teacher Education, 68(1),68. https://doi.org/10.1177/0022487116679959

Richmond, G., Bartell, T., Cho, C., Gallagher, A., He, Y., Petchauer, E., \& Curiel, L. C. (2020). Home/School: Research imperatives, learning settings, and the COVID-19 pandemic. Journal of Teacher Education, 71(5), 503-504.https://doi.org/10.1177/0022487120961574 
Research, Society and Development, v. 10, n. 17, e211101724632, 2021

(CC BY 4.0) | ISSN 2525-3409 | DOI: http://dx.doi.org/10.33448/rsd-v10i17.24632

Rogers, A. A., Ha, T., \& Ockey, S. (2021). Adolescents' perceived socio-emotional impact of COVID-19 and implications for mental health: results from a US-based mixed-methods study. Journal of Adolescent Health, 68(1), 43-52. https://doi.org/10.1016/j.jadohealth.2020.09.039.

Saraiva, L. A. (2015). A relação família-escola sob a perspectiva do professor de ensino fundamental. [Tese. Programa de Psicologia: Universidade Federal Rio Grande do Sul]. Repositório Digital da Universidade Federal do Rio Grande do Sul. https://www.lume.ufrgs.br/handle/10183/130502

Saraiva-Junges, L., \& Wagner, A. (2013). A Relação Família-Escola sob a ótica de professores e pais de crianças que frequentam o ensino fundamental. Ensaio: Avaliação e Políticas Públicas em Educação. 21(81), 739-772. https://doi.org/10.1590/S0104-40362013000400006

Smith, T. E., Sheridan, S. M., Kim, E.M., Park, S., \& Beretvas, N. (2020). The effects of family-school partnership interventions on academic and socialemotional functioning: a meta-analysis exploring what works for whom. Educ Psychol Rev, 32, 511-544. https://doi.org/10.1007/s10648-019-09509-w

Wagner, A., Tornaría, M. D. L. G., Junges, L. A. S., \& Hernandéz, E. (2019). Los docentes frente a las demandas de las familias: aproximando contextos (Teachers face the demands of families: approaching contexts). Revista Eletrônica de Educação,13(2). https: doi.org/10.14244/198271992543

Willemse, T. M., Thompson, I., Vanderlinde, R., \& Mutton, T. (2018). Family-school partnerships: a challenge for teacher education. Journal of Education for Teaching, 44 (3),252-257. http://doi.org/10.1080/02607476.2018.1465545

Yunes, M. A. M., Garcia, N. M., \& Albuquerque, B. D. M. (2007). Monoparentalidade, pobreza e resiliência: entre as crenças dos profissionais e as possibilidades da convivência familiar. Psicologia: Reflexão e crítica,20, 444-453. https://doi.org/10.1590/S0102-79722007000300012

Yunes, M. A. M., \& Szymanski, H. (2003). Crenças, sentimentos e percepções acerca da noção de resiliência em profissionais da saúde e da educação que atuam com famílias pobres. Psicologia da Educação, 17, 119-137. https://revistas.pucsp.br/psicoeduca/article/view/30846 